\title{
Physiological and Anatomical Characterization of a Late-storage Root-forming Mutant of Sweetpotato
}

\author{
Makoto Nakatani, ${ }^{1}$ Masaru Tanaka, and Masaru Yoshinaga \\ Department of Upland Farming, Kyushu National Agricultural Experiment Station, Yokoichi-cho 6644, \\ Miyakonojo, Miyazaki 885-0091, Japan
}

\begin{abstract}
AdDITIONAL INDEX wORDS. Ipomoea batatas, cytokinin, zeatin riboside, grafting
Abstract. A late-storage root-forming mutant ('KM95-A68') of sweetpotato [Ipomoea batatas (L.) Poir.] was characterized to clarify the genetic and physiological mechanisms of storage root formation. This mutant originated from a somaclonal mutation of 'Kokei No. 14'. Storage roots of 'KM95-A68' are rare and, when formed, develop 2 or 3 weeks later than those of 'Kokei No. 14' from which it originated. Morphological characteristics of the canopy and leaf photosynthetic rates of 'KM95-A68' were similar to those of 'Kokei No. 14'. No apparent differences were observed in the anatomy of root cross sections of 'KM95-A68' and 'Kokei No. 14'. An apparent increase in the root zeatin riboside (ZR) levels were observed in 'Kokei No. 14' at storage root formation. Root ZR levels differed between 'Kokei No. 14' and 'KM95-A68'. The onset of increase in root ZR levels was delayed by 2 or 3 weeks in 'KM95-A68' in comparison to 'Kokei No. 14'. Maximum root ZR levels in 'Kokei No. 14' were 2.2 times higher in comparison to 'KM95-A68'. This appeared to be a factor in delayed storage root formation of ' $\mathrm{KM95-A68}$ '. Results of reciprocal grafts of ' $\mathrm{KM95-A68}$ ' and 'Kokei No. 14' indicated that the late storage root-forming characteristic of 'KM95-A68' is a characteristic that arises from the root itself.
\end{abstract}

The most economically important developmental process in sweetpotato (Ipomoea batatas) is storage root formation. Understanding the mechanisms involved is critical to improving yield and quality. Previous research documents the anatomical development of storage root formation and thickening (Kokubu, 1973; Togari, 1950; Wilson and Lowe, 1973). At first, roots increase cambium activity and suppress lignification of the stele. Subsequently, rapid thickening results from active division of anomalous cambium in the root xylem.

Physiologically, cytokinins, especially t-zeatin riboside (ZR), may regulate storage root formation in sweetpotato (Matsuo et al., 1983, 1988; Nakatani and Komeichi, 1991; Sugiyama and Hashizume, 1989; Suye et al., 1983). A rapid increase in endogenous ZR occurs in sweetpotato roots simultaneously with storage root formation. Endogenous ZR is concentrated around the root primary cambium, which plays an important role in storage root formation (Nakatani and Matsuda, 1992). Exogenous applications of cytokinins were reported to be effective in promoting storage root formation (McDavid and Alamu, 1980; Nakatani, 1994; Spence and Humphries, 1972). In short, it is highly likely that cytokinins are involved in storage root formation. Yet, there are no reports on effects of removal or suppression of cytokinins on storage root formation. We contend that mutants that exhibit abnormal storage root development are uniquely suitable for clarifying the role of cytokinins in storage root formation.

We collected many sweetpotato mutants from the Kyushu area in Japan to establish suitable research material for this study. A mutant clone was found among our collection, 'KM95-A68', as a late storage root forming mutant. Therefore, the objectives of this study were to characterize this mutant both anatomically and physiologically to investigate its value as material for genetic or physiological research by studying the involvement of $\mathrm{ZR}$ in storage root formation in sweetpotato.

Received for publication 10 Apr. 2001. Accepted for publication 26 Nov. 2001. We thank D.R. LaBonte, Louisiana State University, Baton Rouge, for critical reading of the English version of this paper.

${ }^{1}$ Current address: National Institute of Crop Science, Tsukuba, Ibaraki 305-8518, Japan.

\section{Materials and Methods}

Plant materials. 'KM95-A68' originated as a regenerated plant from embryogenic callus of 'Kokei No. 14' in 1995 at the Kyushu National Agricultural Experiment Station, Miyazaki, Japan. 'Kokei No. 14' is one of the most popular sweetpotato cultivars in Japan. 'KM95-A68' was found to be a mutant that rarely formed storage roots. The rare storage root-forming characteristic of this mutant line was stable over 4 years. The morphological characteristics of the canopy of 'KM95-A68' are similar to those of 'Kokei No. 14'.

Stem cuttings of 'KM95-A68' were multiplied from lateral branches in a greenhouse. Stem cuttings of 'Kokei No. 14', were derived from storage root sprouts.

Growth Expт. 1. The lower two nodes of a stem cutting with seven nonfolded leaves was inserted into a volcanic ash soil in a plastic pot $(\approx 6 \mathrm{~L})$ on 21 July 1998 . Ten grams of a $3 \mathrm{~N}-10 \mathrm{P}-10 \mathrm{~K}$ fertilizer was applied per pot. They were grown in natural outdoor conditions. Four, 6 , and 8 weeks after planting, four plants of both clones were sampled to determine the beginning of storage root formation. Roots $>5 \mathrm{~mm}$ in diameter were regarded as storage roots (Wilson and Lowe, 1973). The number and weight of the storage roots were recorded.

Growth ExPT. 2. The lower two nodes of a stem cutting with seven nonfolded leaves were transplanted into a $6-\mathrm{L}$ pot containing vermiculite on 26 May 1999 and grown in a temperaturecontrolled greenhouse. The daytime (0600 to $1800 \mathrm{HR}$ ) temperature was maintained at $27^{\circ} \mathrm{C}$, and the nighttime ( 1800 to $0600 \mathrm{HR}$ ) temperature was maintained at $23{ }^{\circ} \mathrm{C}$. Relative humidity was controlled at $70 \%$ during the experiment. Water and mineral nutrients were supplied using the method described by Oyanagi et al. (1987). The canopies were supported with props to avoid mutual shading. Twenty five plants each of 'KM95-A68' and the control, 'Kokei No. 14', were randomly repositioned weekly in the greenhouse to minimize differences in microenvironment.

The photosynthetic rate of the fifth nonfolded leaf of five plants for each clone was measured 5 weeks after planting, using an SPB-4 portable photosynthesis and transpiration meter with a PCL-4B leaf chamber (Shimazu Corp., Kyoto, Japan). The pho- 
tosynthetic photon flux of photosynthetic active radiation (400 to $700 \mathrm{~nm}$ ) was 1500 to $2100 \mu \mathrm{mol} \cdot \mathrm{m}^{-2} \cdot \mathrm{s}^{-1}$ during measurement.

At 2, 3, 4, 5, and 6 weeks after planting, six, six, four, four, and four plants of each clone, respectively, were sampled at random. Their roots were classified into three categories according to the diameter as follows: fibrous root ( $<2 \mathrm{~mm})$, thick root ( 2 to $5 \mathrm{~mm}$ ), and storage root (>5 mm) (Wilson and Lowe, 1973). Maximum root diameter, number, and fresh weight were recorded for each category. The root samples were subjected to anatomical characterization and ZR analysis immediately after weighing.

GrAFTING EXPERIMENT. A grafting experiment was conducted to determine if the storage root mutation in 'KM95-A68' developed via a mutation that affects primarily the plant canopy and/ or the root sphere. Reciprocal grafts of 'KM95-A68' and 'Kokei No. 14' were prepared using the following procedure. Stem cuttings of the stock with six or seven nonfolded leaves were planted and grown for 3 to 5 weeks under the same conditions as those in growth Expt. 2. Stock plants with more than eight nonfolded leaves were then selected and cut at the fifth internode from the soil level. Cleft grafting was done at the fifth internode of the stock with a cutting of the scion line with three nonfolded leaves. All the leaves of the stock were removed at this time. Grafted plants were then cut again at ground level and planted on 11 June 1999 in vermiculite as in growth Expt. 2. Six replicates each of 'KM95-A68' and the control, 'Kokei No. 14', were grown in the greenhouse and assayed as in growth Expt. 2.

Anatomical Characterization. The thickest parts of the roots were cut into small pieces $(<5 \times 5 \times 5 \mathrm{~mm})$ and fixed in 5 formalin : 5 acetic acid : $90(70 \%)$ ethanol (v/v) at least for 1 week at $4{ }^{\circ} \mathrm{C}$ in the dark. These were dehydrated with an ethanol series and cleared by xylen. After embedding in paraffin, cross sections $10 \mu \mathrm{m}$ thick were cut. The sections were stained by safranin and fast green FCF in the usual manner. They were observed under a light microscope (E600; Nikon Corp., Tokyo, Japan).

ZR ANALYSIS. Techniques for ZR analysis were adapted from those described by Nakatani and Komeichi (1991). Root samples $(2 \mathrm{~g})$ were collected from each experiment and stored at $-80^{\circ} \mathrm{C}$. They were homogenized in $10 \mathrm{~mL}$ of $80 \%$ methanol containing $10 \mathrm{mg} \cdot \mathrm{L}^{-1}$ butylated hydroxy toluene at $4{ }^{\circ} \mathrm{C}$ using a Polytron PT1200C (Kinematica AG, Luzern, Switzerland). They were extracted overnight at $4{ }^{\circ} \mathrm{C}$ in the dark. The centrifuged $\left(2,000 g_{\mathrm{n}}\right.$ for $5 \mathrm{~min}$ ) residuals were extracted twice with $5 \mathrm{~mL}$ of $80 \%$ methanol. The supernatants were combined and adjusted to 25 $\mathrm{mL}$ with $80 \%$ methanol. The extracts were then stored at $-20{ }^{\circ} \mathrm{C}$ and the resulting precipitates were removed by centrifugation $\left(12,000 g_{n}\right.$ for $10 \mathrm{~min}$ at $\left.4{ }^{\circ} \mathrm{C}\right)$. A $125-\mu \mathrm{L}(10-\mathrm{mg}$ sample weight equivalent) aliquot was taken and dried at $40{ }^{\circ} \mathrm{C}$ in vacuo. Residues were dissolved in $1 \mathrm{~mL}$ of tris-buffered saline ( $\mathrm{pH} 7.5)$. The ZR concentrations of these solutions were determined using a Phytodetek t-ZR kit (Agdia, Inc., Elkhart, Ind.).

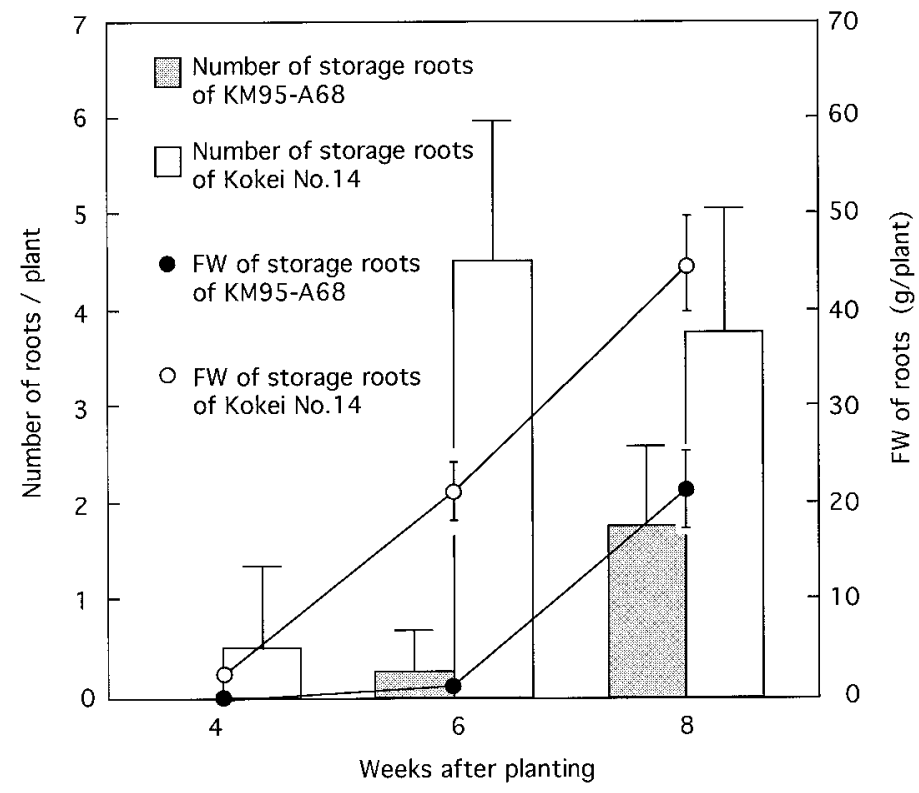

Fig. 1. Changes in the number and FW of storage roots of 'KM95-A68' and 'Kokei No. 14' sweetpotato in 1998 (growth Expt. 1). Each value represents mean $\pm \mathrm{SE}$ of four plants.

Statistical analysis. All statistical calculations were performed using SPSS 10.0J for Windows Base System and Advanced Models (SPSS Inc., Tokyo). Data from the grafting experiment were analyzed using two-way analysis of variance (ANOVA) for a completely randomized design.

\section{Results}

Growth ExpT. 1. In the outdoor conditions in 1998, storage roots began to be observed 4 weeks after planting of 'Kokei No. 14 ' and from 6 weeks after planting of the mutant clone 'KM95A68' (Fig. 1). The number of storage roots reached four per plant at week 6 in 'Kokei No. 14'. It reached two per plant 8 weeks after planting for the mutant. Trends in the increase in storage root weight after its formation were similar between the two clones.

Growth Expт. 2. 'KM95-A68' and 'Kokei No. 14' grown in a greenhouse in 1999 did not differ significantly in stem lengths or photosynthetic rates (Table 1). Root diameter increased exponentially in 'Kokei No. 14' and exceeded 2 mm 3 weeks after planting and $5 \mathrm{~mm} 4$ weeks after planting (Fig. 2). This is consistent with previous reports (Kokubu, 1973; Nakatani and Komeichi, 1991; Togari, 1950; Wilson and Lowe, 1973). The number of thick roots per plant of 'Kokei No. 14' reached a maximum (3.8 per plant) at week 4 and decreased thereafter (Table 2). Storage roots also appeared at the fourth week. 'Kokei

Table 1. Stem length and photosynthetic rate of the fifth nonfolded leaf of 'KM95-A68' and 'Kokei No.14' sweetpotato 5 weeks after planting in 1999 (Growth Expt. 2).

\begin{tabular}{|c|c|c|c|c|c|c|}
\hline \multirow[b]{3}{*}{ Clone } & \multicolumn{5}{|c|}{ Stem length $(\mathrm{cm})^{z}$} & \multirow{3}{*}{$\begin{array}{l}\text { Photosynthetic rate } \\
\left(\mathrm{CO}_{2}, \mu \mathrm{mol} \cdot \mathrm{m}^{-2} \cdot \mathrm{s}^{-1}\right)\end{array}$} \\
\hline & \multicolumn{5}{|c|}{ Weeks after planting } & \\
\hline & 2 & 3 & 4 & 5 & 6 & \\
\hline KM95-A68 & $42.5 \pm 13.0$ & $51.0 \pm 8.1$ & $74.5 \pm 30.7$ & $101.3 \pm 40.8$ & $175.0 \pm 47.3$ & $14.36 \pm 2.38$ \\
\hline Kokei No.14 & $38.5 \pm 4.5$ & $47.7 \pm 11.3$ & $83.0 \pm 19.9$ & $105.8 \pm 26.2$ & $111.0 \pm 22.2$ & $15.12 \pm 3.68$ \\
\hline
\end{tabular}

${ }^{\mathrm{z}}$ Stem length values are means \pm SE of six plants at 2 or 3 weeks or four plants at 4,5 , or 6 weeks after planting.

yValues of photosynthetic rates are means \pm SE of five plants. 


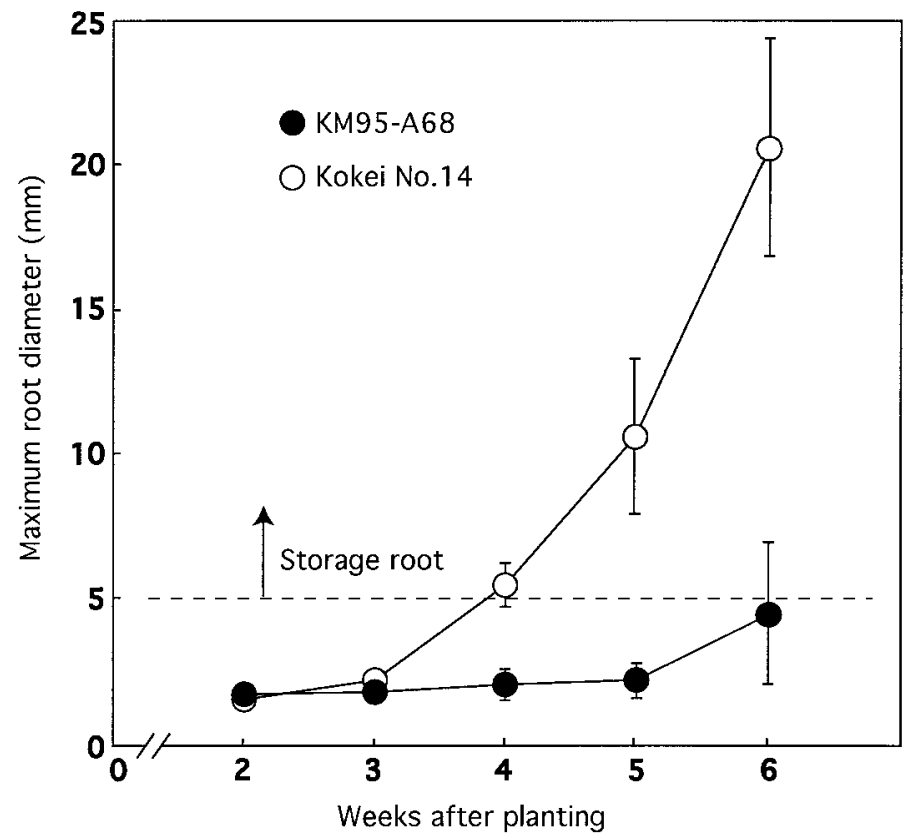

Fig. 2. Changes in maximum root diameter of 'KM95-A68' and 'Kokei No. 14' sweetpotato in 1999 (growth Expt. 2). Each value represents mean \pm SE of six plants at 2 or 3 weeks after planting and four plants at 4, 5, or 6 weeks after planting. The dotted line indicates size criteria of storage roots used in the current study.

No. 14' formed about six storage roots per plant 6 weeks after planting. In contrast, root diameter of 'KM95-A68' increased slowly until week 5 (Fig. 2). A thick root also appeared in this mutant 3 weeks after planting, however, it was the only one among six plants (Table 2). Root diameter increased in 'KM95A68' after week 5, but the average value did not exceed $5 \mathrm{~mm}$ even at the sixth week (Fig. 2). Although storage roots appeared in the sixth week, the average number of storage roots per plant of 'KM95-A68' was less than one (Table 2).

'KM95-A68' was always greater than 'Kokei No. 14' in fresh weight of the fibrous roots, except at the second week (Fig. 3). Fresh weight of the thick roots of 'Kokei No. 14' reached a maximum at the fourth week and that of 'KM95-A68' increased slowly. Fresh weight of the storage roots in 'Kokei No. 14' increased exponentially after their appearance (4 weeks after planting) and exceeded the weight of the fibrous roots at 6 weeks after planting. That of 'KM95-A68' at 6 weeks after planting was $10 \%$ that of the fibrous roots.

Photomicrographs of cross sections of fibrous, thick, and storage roots of 'KM95-A68' and 'Kokei No. 14' are presented in Fig. 4. The fibrous roots $(<2 \mathrm{~mm}$ diameter) of both clones showed the typical anatomy of young sweetpotato roots, i.e., the root stele was relatively small and the metaxylem and metaphloem were recently differentiated (Kokubu, 1973; Togari, 1950; Wilson and Lowe, 1973). The anatomy of the fibrous roots was similar between clones (Fig. 4A and B). When we compared the anatomy of the thick roots and the storage roots between both clones, which had similar diameters but different sampling dates, there were no apparent differences in the anatomy of the roots. Circular primary cambia were observed in the thick roots ( 2 to 5 $\mathrm{mm}$ in diameter) of the two clones (Fig. 4C and D). An active anomalous secondary meristem, i.e., a meristem around the vessel or secondary cambium, was observed in the storage root (>5 mm diameter) xylem of both clones. No apparent anatomical differences were found in the storage roots of the two clones (Fig. $4 \mathrm{E}$ and $\mathrm{F}$ ).

The ZR contents of the fibrous roots of both clones were stable ( $\approx 40 \mathrm{pmol} \cdot \mathrm{g}^{-1}$ fresh weight) throughout the study (Fig. 5). The ZR content of the thick roots in 'Kokei No. 14' increased to twice that of the fibrous roots at initiation. At 6 weeks after planting, the ZR content of 'Kokei No. 14' storage roots was approximately four times that of the fibrous roots at initiation. The ZR content of thick or storage root decreased gradually after their appearance in 'Kokei No. 14'. The ZR contents of the thick and storage roots were slightly higher than those of the fibrous roots in 'KM95A68'. When the thick roots began to appear, the ZR contents of the thick or storage roots tended to be higher in 'Kokei No. 14' than in 'KM95-A68'.

GRAFTING EXPERIMENT. Roots of grafted plants 6 weeks after planting are illustrated in Fig. 6. The two-way ANOVA indicated that both the scion and the stock effects were significant for stem lengths (Table 3 ). The longest vines were observed in grafts with the scion and stock of 'KM95-A68'. Significant effects for maximum root diameter were observed only with the stock effect. Root diameter was larger in the grafts with 'Kokei No. 14' as a stock. The stock effect was also significant for the number of thick roots, and the grafts with 'KM95-A68' stock showed a greater number of thick roots in comparison to 'Kokei No. 14' stock. Significant effects for the number of storage roots were observed for the stock effect, and grafts with 'Kokei No. 14' stock formed more storage roots in comparison to the 'KM95-A68' stock. Only the stock effects were significant for weights of the fibrous and thick roots, and the grafts with 'KM95-A68' stock had greater fibrous and thick root fresh weights in comparison to 'Kokei No. 14 ' stock. Both the scion effect and the stock effect were significant for the storage root weight, and it was highest in the grafts with the scion and stock of 'Kokei No. 14'.

The ZR contents of the fibrous roots of the grafts were $\approx 50$

Table 2. Changes in the number of thick ( 2 to $5 \mathrm{~mm}$ diameter) and storage( $>5 \mathrm{~mm}$ diameter) roots of 'KM95-A68' and 'Kokei No.14' sweetpotato in 1999 (Growth Expt. 2).

\begin{tabular}{|c|c|c|c|c|}
\hline \multirow{2}{*}{$\begin{array}{l}\text { Weeks } \\
\text { after } \\
\text { planting }\end{array}$} & \multicolumn{2}{|c|}{$\begin{array}{c}\text { Thick roots } \\
\text { (no.) }\end{array}$} & \multicolumn{2}{|c|}{$\begin{array}{l}\text { Storage roots } \\
\text { (no.) }\end{array}$} \\
\hline & KM95-A68 & Kokei No.14 & KM95-A68 & Kokei No.14 \\
\hline 2 & 0 & 0 & 0 & 0 \\
\hline 3 & $0.2 \pm 0.4^{\mathrm{z}}$ & $1.2 \pm 1.6$ & 0 & 0 \\
\hline 4 & $1.5 \pm 1.3$ & $3.8 \pm 0.5$ & 0 & $2.0 \pm 1.8$ \\
\hline 5 & $1.0 \pm 0.8$ & $1.8 \pm 1.0$ & 0 & $2.8 \pm 1.5$ \\
\hline 6 & $3.5 \pm 2.6$ & $2.0 \pm 2.2$ & $0.8 \pm 1.0$ & $5.8 \pm 1.0$ \\
\hline
\end{tabular}

${ }^{\mathrm{z} V a l u e s}$ are means \pm SE of six plants at 2 or 3 weeks or four plants at 4, 5, or 6 weeks after planting. 


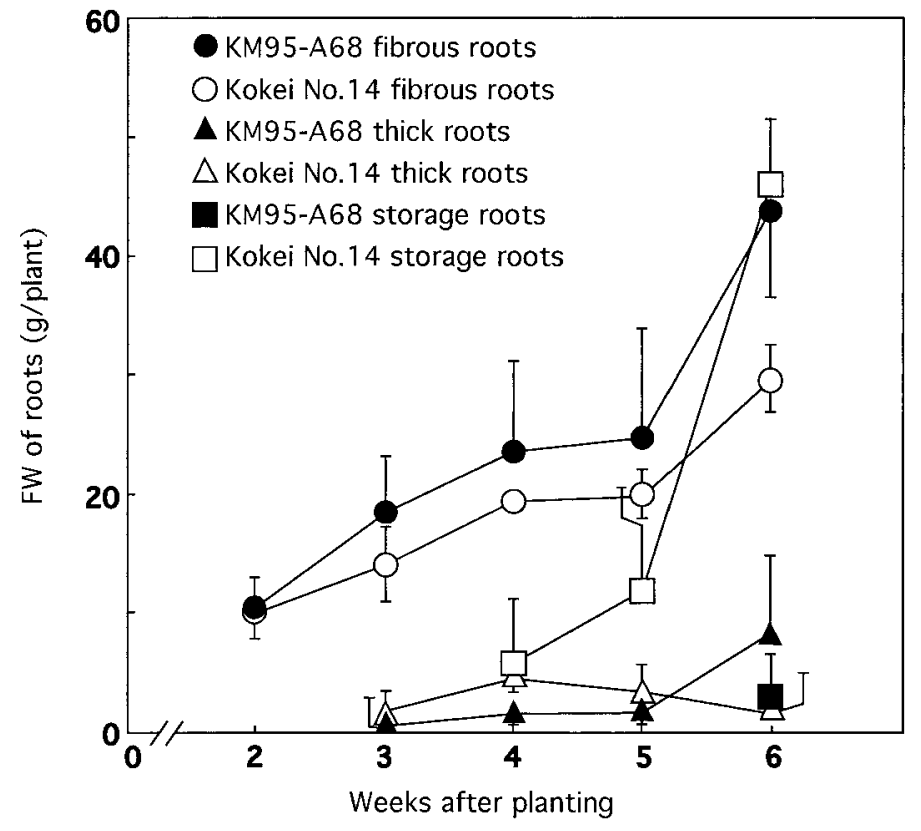

Fig. 3. Changes in fresh weight of fibrous, thick and storage roots of 'KM95-A68' and 'Kokei No. 14' sweetpotato in 1999 (growth Expt. 2). Each value represents mean \pm SE of six plants at 2 or 3 weeks after planting and four plants at 4,5 , or 6 weeks after planting.

$\mathrm{pmol} \cdot \mathrm{g}^{-1}$ fresh weight and did not differ significantly between treatments (Table 3). No significant differences were observed in the ZR content of the thick roots, which was $\approx 90 \mathrm{pmol} \cdot \mathrm{g}^{-1}$ fresh weight. Only the stock effect was significant for the ZR content of the storage roots. Grafts with 'Kokei No. 14' stock showed higher ZR content in the storage roots in comparison to the 'KM95-A68' stock.

\section{Discussion}

Results of the current study indicated that 'KM95-A68' sweetpotato is a late-storage root-forming mutant. Storage root formation in 'KM95-A68' appeared $\geq 2$ weeks after storage root formation occurred in 'Kokei No. 14' under natural (Fig. 1) or controlled (Table 2) environment. Togari (1950) demonstrated that storage root formation can be delayed by a shortage of assimilate supply; however, we found no significant differences between the clones for leaf photosynthetic rates (Table 1). Therefore, the delay in storage root formation in 'KM95-A68' was not due to a shortage of the photosynthetic potential of the leaves. The longer stem of 'KM95-A68' at the sixth week (Table 1) and the larger amount of fibrous roots after the third week (Fig. 3) may represent an alternative sink for assimilates due to the shortage of sink capacity in the storage roots as observed in grafts with nonstorage root forming Ipomoea trifida (H.B.K) G. Don. stock (Hozyo and Park, 1971).

In the current study, root diameter was used for classification, i.e., roots with diameters $<2 \mathrm{~mm}$ were classified as fibrous roots, those with diameters of 2 to $5 \mathrm{~mm}$ were classified as thick roots, and roots with diameters $>5 \mathrm{~mm}$ were classified as storage roots. Sweetpotato storage roots develop through several anatomical stages. The most important stage is differentiation of the primary cambium (Togari, 1950). Another critical stage is differentiation of the anomalous secondary meristem (Kokubu, 1973; Togari, 1950; Wilson and Lowe, 1973). A well developed circular pri-

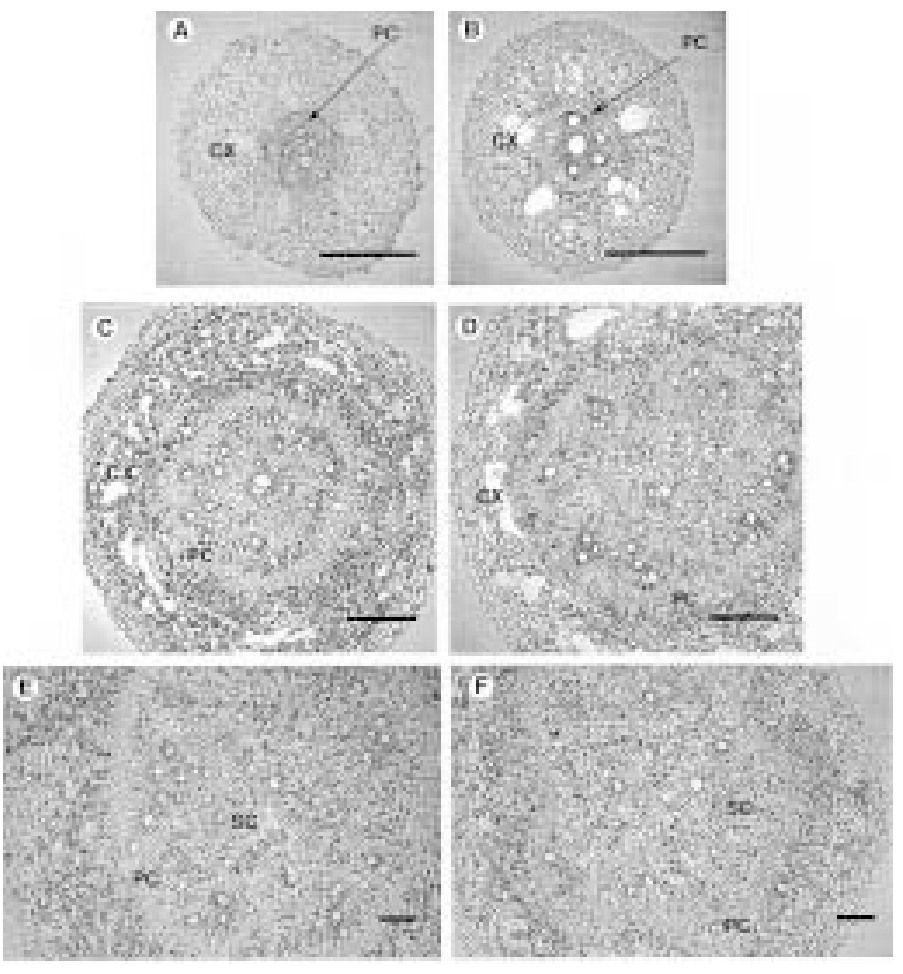

Fig. 4. Photomicrographs of cross sections of fibrous (upper), thick (middle), and storage (lower) root of 'KM95-A68' (left) and 'Kokei No. 14' (right) sweetpotato in 1999 (growth Expt. 2). (A) Fibrous root of 'KM95-A68' 4 weeks after planting, (B) fibrous root of 'Kokei No. 14' 4 weeks after planting, (C) thick root of 'KM95-A68' 5 weeks after planting, (D) thick root of 'Kokei No. 14' 4 weeks after planting, (E) storage root of 'KM95-A68' 6 weeks after planting, and (F) storage root of 'Kokei No. 14' 4 weeks after planting. Bars indicate $0.5 \mathrm{~mm}$. CX $=$ cortex, $\mathrm{PC}=$ primary cambium, $\mathrm{SC}=$ secondary cambium

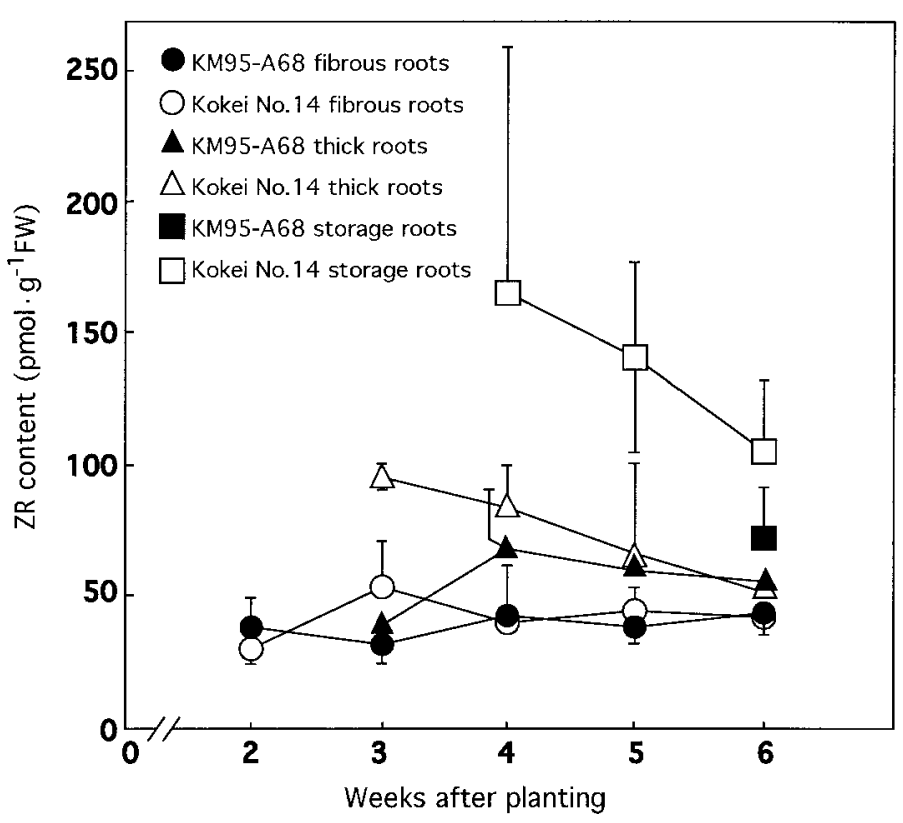

Fig. 5. Changes in the zeatin riboside (ZR) content of fibrous, thick, and storage roots of 'KM95-A68' and 'Kokei No. 14' sweetpotato in 1999 (growth Expt. 2). Each value represents mean \pm SE of six plants at 2 or 3 weeks after planting and four plants at 4,5 , or 6 weeks after planting.

mary cambium was always observed in those roots classified as thick roots in the current study (Fig. 4C and D). Secondary meristems in the xylem were observed in roots classified as 


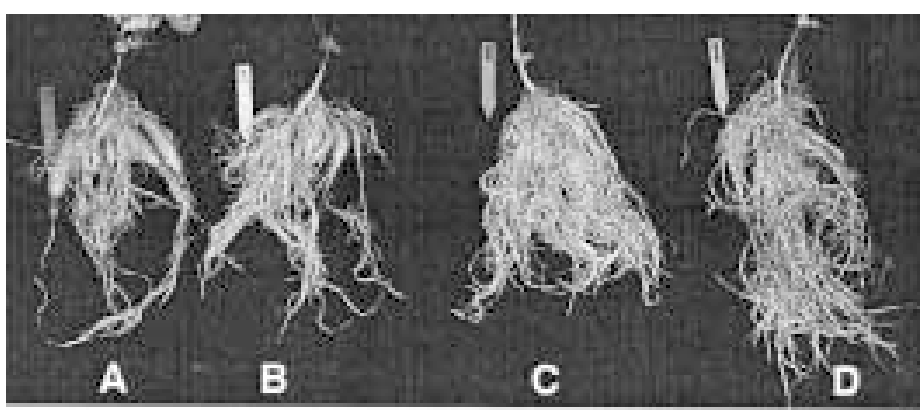

Fig. 6. Roots from reciprocal grafts of sweetpotato 6 weeks after planting (grafting experiment). (A) 'Kokei No. 14' scion and stock, (B) 'KM95-A68' scion and 'Kokei No. 14' stock, (C) 'Kokei No. 14' scion and 'KM95-A68' stock, and (D) 'KM95-A68' scion and stock.

storage roots (Fig. 4E and F).

The active cambium appeared later in 'KM95-A68'. We did not observe, however, any anatomical differences between 'KM95A68' and 'Kokei No. 14' when roots with similar diameters were compared (Fig. 4). Thus, a delay in storage root formation in 'KM95-A68' is not due to a gene mutation that codes essential characteristics that comprise the root anatomy.

It is possible that ' $\mathrm{KM} 95-\mathrm{A} 68$ ' is a regulatory pathway mutant since the data showed no differences in canopy morphology, root anatomy, or assimilate production in comparisons between mutant 'KM95-A68' and 'Kokei No. 14'. Reciprocal grafts between 'KM95-A68' and 'Kokei No. 14' help to locate where the mutation acts, whether in the canopy (scion) or the root sphere (stock). Grafts with 'Kokei No. 14' stock showed a significantly larger number of storage roots than those with 'KM95-A68' stock, and the difference in the scion clone did not significantly affect the number of storage roots (Table 3). Those results indicate that root characteristics have a dominant effect on the number of storage roots in comparison to canopy characteristics in these grafts. Thus, the delay in storage root formation is caused mainly by mutations of characteristics of the root itself. However, both the scion effect and the stock effect were significant for storage root weight (Table 3). Thus, any mutation that occurred in 'KM95-A68' altered storage root formation characteristics but also one or more characteristics of the canopy affected the thickening of the storage root after its formation. These characteristics of the top organ cannot be identified from the results in the current study.

Plant hormones are often involved in regulation of plant development. Many reports have suggested involvement of cytokinins in regulation of storage root formation in sweetpotato (Matsuo et al., 1983, 1988; McDavid and Alamu, 1980; Nakatani, 1994; Nakatani and Komeichi, 1991; Nakatani and Matsuda, 1992; Spence and Humphries, 1972; Sugiyama and Hashizume, 1989; Suye et al., 1983). Endogenous ZR, the major cytokinin in sweetpotato (Matsuo et al., 1983; Sugiyama and Hashizume, 1989; Suye et al., 1983), was assayed in the present study. We observed a rapid increase in root ZR levels in 'Kokei No. 14' at the time of storage root formation (Fig. 5). This is consistent with previous reports (Matsuo et al., 1983, 1988; Nakatani and Komeichi, 1991; Sugiyama and Hashizume, 1989; Suye et al., 1983). In contrast, the increase in root ZR levels in 'KM95-A68' was delayed, and the degree of increase was less (Fig. 5). These results suggest that a mutation in the biosynthesis or the translocation of ZR may cause a delay in storage root formation of 'KM95-A68'.

The stock effect altered not only the number of storage roots, but also changed storage root ZR levels, i.e., it was higher in grafts with the 'Kokei No. 14' stock (Table 3). Differences in storage root ZR levels among the grafts were comparable to differences in storage root number. The correlation coefficient between them was 0.92 . It is well known that one of the most important source organs of cytokinin is the root (Torrey, 1976). It is thus likely that certain root characteristics related to biosynthesis or translocation of ZR have mutated in 'KM95-A68'. The decrease of root ZR level by this mutation might cause a delay in storage root formation. Some reports (McDavid and Alamu, 1980; Nakatani, 1994; Spence and Humphries, 1972) showing the promotive effects of exogenous cytokinin application on storage root formation support this hypothesis. At present, however, we are unable to conclude whether the decrease in ZR level is a cause or a result of delay of storage root formation in 'KM95-A68' without molecular analysis of this mutation.

Although there are many reports suggesting involvement of $\mathrm{ZR}$ in storage root formation, there are no reports regarding the

Table 3. Plant morphology and zeatin riboside (ZR) content for reciprocal grafts of 'KM95-A68' and 'Kokei No.14' sweetpotato, 6 weeks after planting (Grafting experiment). ${ }^{\mathrm{z}}$

\begin{tabular}{|c|c|c|c|c|c|c|}
\hline \multirow{4}{*}{$\begin{array}{l}\text { Grafting } \\
\text { combination }\end{array}$} & \multicolumn{4}{|c|}{ Scion } & \multirow{4}{*}{$\begin{array}{l}\text { Scion } \\
\text { effect }^{y}\end{array}$} & \multirow{4}{*}{$\begin{array}{l}\text { Stock } \\
\text { effect }^{y}\end{array}$} \\
\hline & \multicolumn{2}{|c|}{ KM95-A68 } & \multicolumn{2}{|c|}{ Kokei No. 14} & & \\
\hline & \multicolumn{4}{|c|}{ Stock } & & \\
\hline & KM95-A68 & Kokei No. 14 & KM95-A68 & Kokei No. 14 & & \\
\hline Stem length $(\mathrm{cm})$ & $135.8 \pm 34.5$ & $84.5 \pm 21.1$ & $93.2 \pm 16.8$ & $85.3 \pm 22.2$ & $*$ & $* *$ \\
\hline Maximum root diameter (mm) & $8.4 \pm 3.6$ & $15.3 \pm 3.0$ & $4.2 \pm 1.7$ & $21.4 \pm 1.3$ & NS & $* *$ \\
\hline Number of thick roots/plant & $3.3 \pm 2.5$ & $1.2 \pm 2.0$ & $4.7 \pm 2.8$ & $0.5 \pm 0.8$ & NS & $* *$ \\
\hline Number of storage roots/plant & $3.0 \pm 1.8$ & $4.2 \pm 2.0$ & $1.0 \pm 2.0$ & $5.8 \pm 1.7$ & NS & $* *$ \\
\hline $\mathrm{FW}$ of fibrous roots (g/plant) & $27.4 \pm 5.8$ & $7.2 \pm 3.0$ & $26.9 \pm 10.1$ & $4.7 \pm 1.8$ & NS & $* *$ \\
\hline FW of thick roots (g/plant) & $8.0 \pm 5.1$ & $1.1 \pm 1.9$ & $10.2 \pm 3.6$ & $0.8 \pm 1.2$ & NS & $* *$ \\
\hline $\mathrm{FW}$ of storage roots (g/plant) & $13.2 \pm 11.7$ & $20.0 \pm 8.6$ & $3.1 \pm 6.4$ & $59.3 \pm 15.6$ & $* *$ & $* *$ \\
\hline ZR content of fibrous roots $\left(\mathrm{pmol} \cdot \mathrm{g}^{-1}\right.$ fresh wt) & $67.9 \pm 14.3$ & $56.3 \pm 10.5$ & $49.1 \pm 21.4$ & $52.7 \pm 9.9$ & NS & NS \\
\hline ZR content of thick roots $\left(\mathrm{pmol} \cdot \mathrm{g}^{-1}\right.$ fresh wt) & $88.3 \pm 15.0$ & $110.6 \pm 18.1$ & $86.7 \pm 8.9$ & $85.3 \pm 16.5$ & NS & NS \\
\hline ZR content of storage roots $\left(\mathrm{pmol} \cdot \mathrm{g}^{-1}\right.$ fresh wt) & $125.0 \pm 43.1$ & $194.4 \pm 40.8$ & $114.1 \pm 25.7$ & $206.1 \pm 49.2$ & NS & $* *$ \\
\hline
\end{tabular}

${ }^{\mathrm{z}}$ Values are means \pm SE of six plants.

${ }^{y}$ Results of a two-way ANOVA.

Ns,*,**Nonsignificant or significant at $P \leq 0.05$ or 0.01 , respectively. 
changes in root ZR levels when storage root formation is suppressed or delayed. Results of the current study suggest involvement of ZR in the regulation of storage root formation in sweetpotato. We also demonstrate the utility of 'KM95-A68' as a tool for investigating storage root formation in sweetpotato because it can provide evidence of hormonal regulation of storage root formation. We are presently using this mutant to study the genes related to storage root formation in sweetpotato.

\section{Literature Cited}

Hozyo, Y and C.K. Park. 1971. Plant production in grafting plants between wild type and improved variety in Ipomoea. Bul. Natl. Inst. Agr. Sci. D22:145-164.

Kokubu, T. 1973. Thremmatological studies on the relationship between the structure of tuberous root and its starch accumulating function in sweetpotato varieties. Bul. Faculty Agr. Kagoshima Univ. (Kagoshima) 23:1-126.

Matsuo, T., H. Mitsuzono, R. Okada, and S. Itoo. 1988. Variation in the levels of major free cytokinins and free abscisic acid during tuber development of sweetpotato. J. Plant Growth Regulat. 7:249-258.

Matsuo, T., T. Yoneda, and S. Itoo. 1983. Identification of free cytokinins and the changes in endogenous levels during tuber development of sweetpotato (Ipomoea batatas Lam.). Plant Cell Physiol. 24:13051312.

McDavid, C.R. and S. Alamu. 1980. The effect of growth regulators on tuber initiation and growth in rooted leaves of two sweetpotato cultivars. Ann. Bot. 45:363-364.
Nakatani, M. 1994. In vitro formation of tuberous roots in sweet potato. Jpn. J. Crop Sci. 63:158-159.

Nakatani, M. and M. Komeichi. 1991. Changes in endogenous level of zeatin riboside, abscisic acid and indole acetic acid during formation and thickening of tuberous roots in sweetpotato. Jpn. J. Crop Sci. 60:91-100.

Nakatani, M. and T. Matsuda. 1992. Immunohistochemical localization of zeatin riboside in tuberous root of sweetpotato. Jpn. J. Crop Sci. 61:685-686.

Oyanagi, A., M. Nakatani, and Y. Watanabe. 1987. Studies on the factors inducing cracking in tuberous roots of sweetpotato (Ipomoea batatas Lam.). Jpn. J. Crop Sci. 56:190-197.

Spence, J.A. and E.C. Humphries. 1972. Effect of moisture supply, root temperature, and growth regulators on photosynthesis of isolated rooted leaves of sweetpotato (Ipomoea batatas). Ann. Bot. 36:115121.

Sugiyama, T. and T. Hashizume. 1989. Cytokinins in developing tuberous roots of sweetpotato (Ipomoea batatas). Agr. Biol. Chem. 53:49_ 52.

Suye, S., T. Sugiyama, and T. Hashizume. 1983. Mass spectrometric determination of ribosyl trans-zeatin from sweetpotato tubers (Ipomoea batatas L. cv. Kohkei No. 14). Agr. Biol. Chem. 47:1665-1666.

Togari, Y. 1950. A study in the tuberous-root formation of sweetpotato. Bul. Natl. Agr. Expt. Sta. (Tokyo) 68:1-96.

Torrey, J.G. 1976. Root hormones and plant growth. Annu. Rev. Plant Physiol. 27:435-459.

Wilson, L.A. and S.B. Lowe. 1973. The anatomy of the root system in West Indian sweetpotato (Ipomoea batatas (L.) Lam.) cultivars. Ann. Bot. 37:633-643. 